\title{
A Mobile-ICT platform to deliver psychotherapy to prevent suicide
}

\author{
Dr. R.B. Marasinghe \\ Department of Medical Education, University of Sri Jayewardenepura, Sri Lanka.
}

\section{Dr. S. Edirippulige}

Centre for Online Health, University of Queensland, Australia.

\section{Dr. A. Smith}

Centre for Online Health, University of Queensland, Australia.

\section{Dr. D. Kavangh.}

Institute of Health \& Biomedical Innovation, Queensland University of Technology, Australia.

\section{Prof. M.T.M. Jiffry}

Department of Medical Education, University of Sri Jayewardenepura, Sri Lanka.

\section{G.N. Kodagoda}

Sri Lanka Institute of Information Technology, Sri Lanka.

Contact e-mail address: rohanabm@yahoo.com

eHealth Sri Lanka 2010,1(suppl.1):S9

DOI: http://dx.doi.org/10.4038/sljbmi.v1i0.3542

Only the Abstract is available

\begin{abstract}
Introduction: Use of Information and Communication Technologies (ICT) is becoming popular in many sectors of the society and healthcare is not an exception. Evidence is emerging on the effective use of ICT and mobile devices in healthcare practices. The lack of technology is often cited as a main reason for underutilisation of such services in developing countries. Although, the web technology has multiple uses, it is often expensive to be used widely in developing countries. Alternatively, the mobile phone is one technology which is emerging as an affordable and popular tool of communication. There are advantages in combine use of web and mobile networks.

Objective: Main objective is to develop an affordable Mobile-ICT platform which is capable of delivering health messages from a caregiver directly to the client through the Internet and mobile networks.

Method: Development millstones of the Mobile-ICT platform are as follows. Firstly, the theoretical framework was developed after reviewing present ICT infrastructure, the state of networking including mobile networks as well as considering the user habits in Sri Lanka. Subsequently, the Mobile-ICT platform was customised to deliver a Brief Mobile Treatment, which is designed to prevent suicide. Finally, a Randomised Controlled Trial (RCT) was conducted to test the therapeutic effect of the use of Mobile-ICT platform on a Sri Lankan sample.

Results: Mobile-ICT platform had following features. The end user recipient (e.g. patient) had access to real-time voice messages, pre-recorded voice messages and scheduled Short Message Services (SMSs) using their mobile phones. The sender (eg. Doctor) also had access to real-time voice messages and the sender could control the voice and SMS messages via internet form anywhere in the world.

Conclusion: The Mobile-ICT platform provided an affordable and acceptable method to deliver remote psychological care to prevent suicide in Sri Lanka.
\end{abstract}

Keywords - ICT, SMS messages, Mobile-ICT platform, to prevent suicide 
